Research Article

\title{
Layered Rare-Earth Hydroxide Unilameller Nanosheets: Synthesis, Characterization, and Adsorption
}

\author{
Solomon Omwoma $\mathbb{D}^{1},{ }^{1}$ Adongo Stephen Odongo $\mathbb{D D}^{1}{ }^{1}$ Zablon Otieno $\mathbb{D}^{1},{ }^{1}$ Silas Lagat, ${ }^{1}$ \\ and Joseph Owuor Lalah $\mathbb{D}^{2}$ \\ ${ }^{1}$ Department of Physical Sciences, Jaramogi Oginga Odinga University of Science and Technology, P.O. Box 210-40601, \\ Bondo, Kenya \\ ${ }^{2}$ Department of Chemical Science and Technology, Technical University of Kenya, P.O. Box 52428-00200, Nairobi, Kenya \\ Correspondence should be addressed to Solomon Omwoma; solomwoma@yahoo.com
}

Received 8 May 2019; Revised 7 November 2019; Accepted 16 November 2019; Published 28 January 2020

Academic Editor: Philippe Trens

Copyright (c) 2020 Solomon Omwoma et al. This is an open access article distributed under the Creative Commons Attribution License, which permits unrestricted use, distribution, and reproduction in any medium, provided the original work is properly cited.

\begin{abstract}
Unilameller nanosheets with a lateral dimension of one nanometer have been isolated from a colloidal solution of europiumcontaining layered rare-earth hydroxide (LRH) material by the flocculation method. The nanosheets were achieved by changing $\mathrm{pH}$ of the colloidal solution from 6.7 to 11.5. The resultant flocculated nanosheets show high efficiency in sorption of fluoride anions from aqueous media $(40 \mathrm{mmol} / \mathrm{g})$, providing a potentially useful sorbent material for water purification technology. The sorbent material is demonstrated to be reusable for at least ten times without a significant loss of adsorption efficiency. And the results fit the Langmuir adsorption curve, indicating the chemisorption nature of the nanosheets. Most importantly, the isolated nanosheets are expected to widen the applicability and flexibility in material synthesis using two-dimensional nanomaterials.
\end{abstract}

\section{Introduction}

Synthesis of building blocks used in advancement of material chemistry is highly affected by size, surface, shape, defect properties, and anisotropy. Anisotropy is determined by geometry and structure of self-assembled materials and is sometimes difficult to achieve in nanomaterials. However, there has been progress in synthesis of materials such as the functional oxide nanosheets and exfoliated layered double hydroxides (LDHs) [1-4]. The synthesized nanosheets have been shown to display robust chemical-physical properties such as lateral dimensions of less than $10 \mathrm{~nm}$, high adsorption rates, great catalysts, and high dispersion rates in solvents that make them useful building units in the manufacture of nanodevices [5-7].

Only LDH nanosheets exhibit a positive charge, whereas all the other nanosheets are negatively charged [7]. Delamination of $\mathrm{LDH}$ nanosheets has been reported to occur mainly in formamide solution $[8,9]$. It is noted that delamination of LDHs in aqueous media is difficult due to the high charge density of the LDHs layers and the high anion contents that result in strong interlayer electrostatic interactions between the sheets and the extensive interlamellar hydrogen bonding networks, which lead to a tight stacking of the lamellae $[2,10,11]$. This limits the use of these building units especially for aqueous reactions.

Layered rare-Earth hydroxides (LRHs) have a general formula of $\mathrm{Ln}_{8}(\mathrm{OH})_{20}\left(\mathrm{~A}^{\mathrm{m}-}\right)_{4 / \mathrm{m}} \cdot \mathrm{nH}_{2} \mathrm{O}(\mathrm{Ln}=$ rare-earth ions; $\mathrm{A}=$ intercalated anions). LRHs with one type of $\mathrm{Ln}^{3+}$ cations occupying the octahedral position on the layers can be easily delaminated into individual nanosheets in aqueous media [12-17], which is in good contrast to that of LDHs. Moreover, the sonication of LRHs in the aqueous medium results in the formation of a colloidal solution, which consists of a number of unilameller layers of the positively charged nanosheets of $\left[\mathrm{Ln}_{8}(\mathrm{OH})_{20} \cdot \mathrm{nH}_{2} \mathrm{O}\right]^{4+}[12-14]$. These lamellar positively charged nanosheets are vital building units for the synthesis of LRH-containing functional materials due to their positively charged surfaces. However, these unilameller nanosheets have not been isolated so as to 
extend the novel applicability of positively charged nanosheets.

Herein, a simple new method of isolating the unilameller nanosheets is reported. Stable unilameller nanosheets were isolated by changing the $\mathrm{pH}$ of the colloidal solution from 6.5 to 11.5. The flocculated unilameller nanosheets show good performance for fluoride sorption from aqueous media, providing a potentially useful sorbent material for water purification technology. And we demonstrate the recyclability of this material in fluoride separation from the aqueous medium.

It is important to note that fluoride has detrimental health effects to aquatic life and humans such as cancer, dental fluorosis, bone resorption, endocrine disruption, mutations, and brain damage. [18]. Hence, industries that use fluoride in their processes ought to separate it from wastewater before disposal of the water to aquatic systems.

In addition, although nanosorbents present a great potential in advancing water and wastewater treatment efficiency, most of the nanosorbents reported so far generate secondary wastes which are equally hazardous to the environment [19]. As such, development of recyclable nanosorbents is a big step forward in wastewater treatment efficiency.

\section{Materials and Methods}

2.1. Chemical Materials. Analytically pure $\mathrm{KOH}, \mathrm{NaOH}$, $\mathrm{Eu}_{2} \mathrm{O}_{3}, \mathrm{HCl}, \mathrm{NaF}, \mathrm{KBr}$, lacmoid, ethanol, and methanol were purchased from Alfa Aesar and used without further purification.

2.2. Preparation of Wet $\mathrm{LEuH}-\mathrm{Cl}$. Eu-containing layered rare-Earth hydroxides $\left(\mathrm{Eu}_{2}(\mathrm{OH})_{5} \mathrm{Cl} \cdot \mathrm{nH}_{2} \mathrm{O}\right)(\mathrm{LEuH}-\mathrm{Cl})$ were synthesized and characterized according to literature methods [12]. In brief, $0.1 \mathrm{M} \mathrm{KOH}$ solution was added to $0.05 \mathrm{M} \mathrm{EuCl}_{3} \cdot 6 \mathrm{H}_{2} \mathrm{O}$ solution with stirring at $24^{\circ} \mathrm{C}$. The resultant mixture was heated to $60^{\circ} \mathrm{C}$ for $12 \mathrm{~h}$ and thereafter refluxed for $24 \mathrm{~h}$ as with magnetic stirring. The resultant slurry was washed with deionized water three times in a centrifuge. The solid sample was labeled as wet LEuH-Cl.

2.3. Flocculation. The delamination of fresh prepared wet LEuH-Cl aggregate material was achieved by sonication (3 min @ 100 W) to obtain an aqueous colloidal solution. Sonication beyond these specifications is noted to result into broken delaminated nanosheets. The $\mathrm{pH}$ of the aqueous colloidal solution was adjusted from 6.5 to 11.5 using $1 \mathrm{M}$ $\mathrm{NaOH}$ solution that led to flocculation of unilameller LEuH nanosheets (LEuH-flocs). The contents were centrifuged at $2000 \mathrm{rpm}$, and the residue was washed with distilled water four times before a final wash with acetone followed by vacuum drying at $40^{\circ} \mathrm{C}$.

2.4. Characterization. The $\mathrm{OH}$ content of solid samples was determined titrimetrically by neutralization backtitration after dissolution of the samples in a $0.1 \mathrm{~N}$ standard $\mathrm{H}_{2} \mathrm{SO}_{4}$. Measurements of diffraction patterns of the $40^{\circ} \mathrm{C}$ dried samples were achieved using a Rigaku XRD diffractometer machine $(6000)$ conditioned at $30 \mathrm{~mA}, 40 \mathrm{kV}, \mathrm{Cu}-\mathrm{Ka}$ $(\lambda=0.154 \mathrm{~nm})$, and with a scan step of $0.01^{\circ}$ measured between $3^{\circ}$ and $70^{\circ}$. Surface morphology was observed using a SEM (Zeiss Supra 55) machine simultaneously connected to an EDX detector. In addition, atomic forces were determined using a Bruker AFM machine (A3A) in order to determine lateral dimensions of nanosheets isolated. Crosssectional transverse morphological study was done using a HRTEM machine (Hitachi H-800). High sensitivity elemental analysis in aqueous solutions was performed using ICP-AES machine (ICPS-7500). Solid samples were first digested using aqua regia solutions before ICP-AES analysis. The pore volumes and specific surface area studies for solid samples were done using BET and BJH methods with Quantachrome Autosorb1C VP machine. Before such analyses were done, the solid samples were first degassed at $100^{\circ} \mathrm{C}$ for 6 hrs.

2.5. Adsorption Experiments. The efficiency of fluoride sorption by $\mathrm{LEuH}$-flocs nanosheets was compared to the sorption efficiency of LEuH-Cl aggregates. To a known concentration of fluoride ions in aqueous media, $0.4 \mathrm{~g}$ of test sample was introduced and then the test solution was kept stirring for 1 hour. After that, the nanocomposites were centrifuged down and the supernatant solution was tested for fluoride concentration colorimetrically [20]. The pelleted sample was dried and calcined at $500^{\circ} \mathrm{C}$ for 24 hours to remove the adsorbed fluoride, and the material was reconstituted in a $\mathrm{NaCl}$ solution to regenerate the $\mathrm{LEuH}-\mathrm{Cl}$ material through the "memory effect" method of hydrotalcites [7]. Direct adsorption of the fluoride ions by the calcined LEuH-flocs was also determined.

\subsection{Kinetic Studies}

2.6.1. Determination of Adsorption Rate and Equilibrium. Ten samples of fluoride ions dissolved in deionized water (100 ppm) were treated with $0.2 \mathrm{~g}$ of $\mathrm{LEuH}$-flocs for $0,1,2,3$, $4,5,6,8,10$, and 15 minutes. After each experiment, the $\mathrm{LEuH}$-flocs were separated and the resultant supernatant was tested for fluoride concentration. A similar experiment was repeated for the $\mathrm{LEuH}-\mathrm{Cl}$ aggregate material.

2.6.2. Adsorption Isotherms. The test samples $(0.2 \mathrm{~g})$ were stirred with $50 \mathrm{ml}$ solutions having different concentrations $(1,5,10,20,50,100,200,300,400,500$, and $1000 \mathrm{ppm})$ of fluoride anions for 30 minutes to insure equilibrium. The nanocomposites were centrifuged, and the supernatant was tested for fluoride concentration. The amount of fluoride uptaken per gram of the LEuH-flocs $(q)$ was determined according to the following equation, where $C_{0}$ is the initial fluoride concentration, $C$ is the concentration of the equilibrated final solution, $V$ is the volume of the aqueous phase, and $m$ is the mass of the adsorbent in the system:

$$
q=\frac{\left(C_{0}-C\right) V}{m} \text {. }
$$




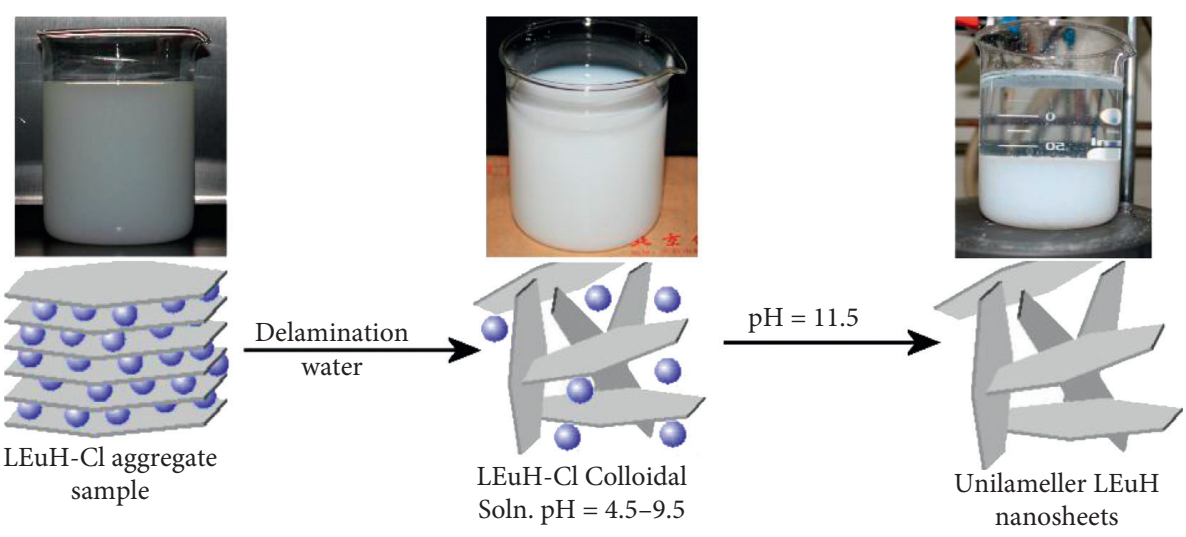

Figure 1: The flocculation process generating LEuH-flocs nanosheets through $\mathrm{pH}$ adjustments.

\section{Results and Discussion}

3.1. Characterization of the Nanocomposite Materials. Adjusting the $\mathrm{pH}$ of a colloidal solution, sonicated from freshly prepared wet $\mathrm{LEuH}-\mathrm{Cl}$ aggregates, from $\mathrm{pH}=6.5$ to $\mathrm{pH}=11.5$ resulted into flocculation of unilameller $\mathrm{LEuH}$ nanosheets (LEuH-flocs) (Figure 1). During the $\mathrm{pH}$ adjustment experiments, there was no observable change between $\mathrm{pH} 4.5$ and $\sim 9.5$. However, below $\mathrm{pH} 4.5$, the nanosheets decomposed to individual elements. Chemical analysis of LEuH-flocs reveal an elemental composition of $\mathrm{Eu}_{8}(\mathrm{OH})_{20}\left(\mathrm{CO}_{3}\right)_{0.67}\left(\mathrm{H}_{2} \mathrm{O}\right)_{4.4} \mathrm{Cl}_{3.15}$, which is simplified as $\left[\mathrm{Eu}_{8}(\mathrm{OH})_{20}\left(\mathrm{H}_{2} \mathrm{O}\right)_{4.4}\right] \mathrm{Cl}_{4}$. The composition resembles that of the starting material (LEuH-Cl aggregates).

SEM images of both LEuH-flocs nanosheets and LEuH$\mathrm{Cl}$ aggregates show similarity in plate-like morphology with the former exhibiting unilameller platelets, while the latter is organized in layers ranging from $20 \mathrm{~nm}$ to $65 \mathrm{~nm}$ (Figure 2). Energy dispersive X-ray spectroscopy (EDX) images provide further evidence of composition similarity (Figure 2). However, TEM images show the unilameller nature of the LEuH-flocs (Figure 2).

The unilameller character of the LEuH-flocs can also be clearly distinguished from the layered character of $\mathrm{LEuH}-\mathrm{Cl}$ aggregates by HRTEM images (Figure 3 ). And the selected area electron diffraction (SAED) patterns of LEuH-flocs are much clearer than that of $\mathrm{LEuH}-\mathrm{Cl}$ aggregates, indicating the high crystallinity of the LEuH-flocs nanosheets (Figure 3). Despite the crystallinity differences, it is evidently clear from the SAED patterns that atomic arrangement remains the same in both samples (Figure 3 ). The atoms are arranged in a pseudohexagonal symmetry with a unit fundamental cell of $a_{\mathrm{f}}=3.7 \AA$. It can be calculated that $d_{100}=2 \sqrt{ } 3 a_{\mathrm{f}}=12.8 \AA$ and $d_{010}=2 a_{\mathrm{f}}=7.4 \AA$. These particular atomic distances are further verified by XRD diffraction patterns shown in Figure 4.

The LEuH-Cl aggregate sample exhibits XRD patterns that can be indexed as a single orthorhombic unit cell with lattice parameters of $a=12.90 \AA\left(d_{100}\right), b=7.52 \AA\left(d_{010}\right)$, and $c=8.63 \AA\left(d_{001}\right)$. These values clearly correspond to the calculated values from SAED patterns in Figure 3. Since the LEuH-flocs exist as unilameller layers, it is almost impossible to distinguish the $d_{100}$ and $d_{010}$ reflections in the XRD patterns; however, the $d_{001}=7.6 \AA$ reflection is clear with a very high intensity indicating the nanosheets to lie on their $c$ plane. Nevertheless, there is no restacking because no $d_{001}$ harmonics were observed. And it is worth noting that the results of $\mathrm{LEuH}-\mathrm{Cl}$ aggregates are in good agreement with literature [17].

The AFM images of a colloidal solution for both LEuHflocs and $\mathrm{LEuH}-\mathrm{Cl}$ aggregates dispersed on wafer plates show the width of LEuH-flocs to be approximately $1 \mathrm{~nm}$, while LEuH aggregates are approximately $26 \mathrm{~nm}$ (Figure 5). Dispersion of the LEuH-flocs nanosheets in water at $\mathrm{pH}=7$ results into a colloidal solution indicating the nanosheets to maintain both their nanoscale size and their charge (Figure 5(c)).

FTIR vibrations show an intense absorption band at $3494 \mathrm{~cm}^{-1}$ attributed to $\mathrm{O}-\mathrm{H}$ bond, $v(\mathrm{OH})$, stretching in both the LEuH-flocs nanosheets and $\mathrm{LEuH}-\mathrm{Cl}$ aggregates (Figure 6). The vibration band at $1634 \mathrm{~cm}^{-1}$ is due to the bending mode of both surface and interlayer water (see Figure 7 for water contents). Two sharp bands at 1511 and $1454 \mathrm{~cm}^{-1}$ in $\mathrm{LEuH}-\mathrm{Cl}$ aggregates are attributed to $\mathrm{CO}_{3}{ }^{2-}$ vibrations in a layered structure [13]. However, there exists a shift in these $\mathrm{CO}$ vibrations and a decrease in sharpness which is indicative of the lack of stacking in the LEuH-flocs nanosheets [13]. Two shoulder peaks at 848 and $818 \mathrm{~cm}^{-1}$ are due to interlayer chloride anions, while the bands at 638 and $535 \mathrm{~cm}^{-1}$ are attributed to Eu-O stretching. In addition, the O-C-O bending mode may have shifted from 526 to $535 \mathrm{~cm}^{-1}$ due to lack of stacking. Furthermore, the band at $1374 \mathrm{~cm}^{-1}$ in LEuH-flocs and LEuH-flocs + fluoride might arise from adsorbed $\mathrm{CO}_{3}{ }^{2-}$.

Thermogravimetric analysis of $\mathrm{LEuH}$-flocs and $\mathrm{LEuH}-\mathrm{Cl}$ aggregates clearly show the difference in interlayer water content of the two samples (Figure 7). Interlayer water is used in stacking of layers together by creating hydrogen bonding networks with anions within the layers. However, the LEuH-flocs has very little of these water content indicating their unilameller property (Figure 7).

The isolation of LEuH-flocs nanosheet is further verified by the difference in pore volume as compared to the LEuH$\mathrm{Cl}$ aggregates (determined by Brunauer-Emmett-Teller 

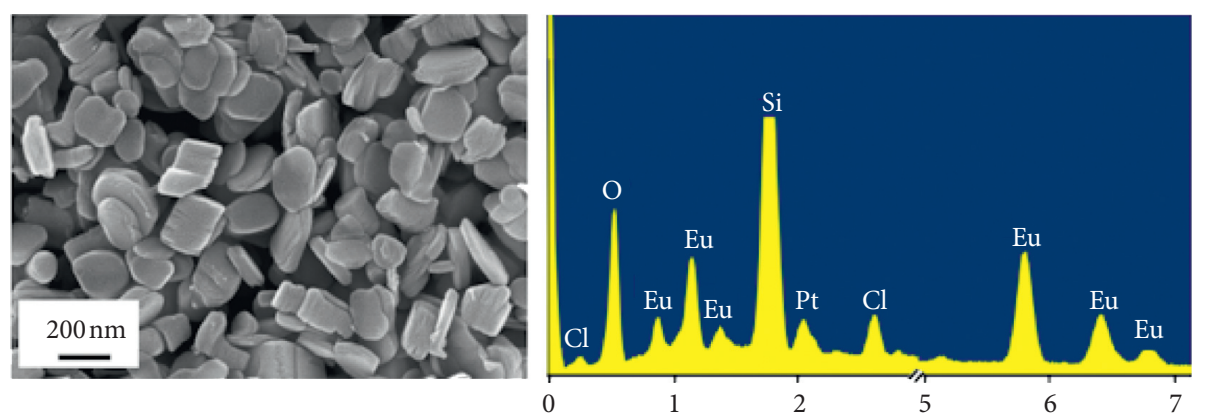

(a)
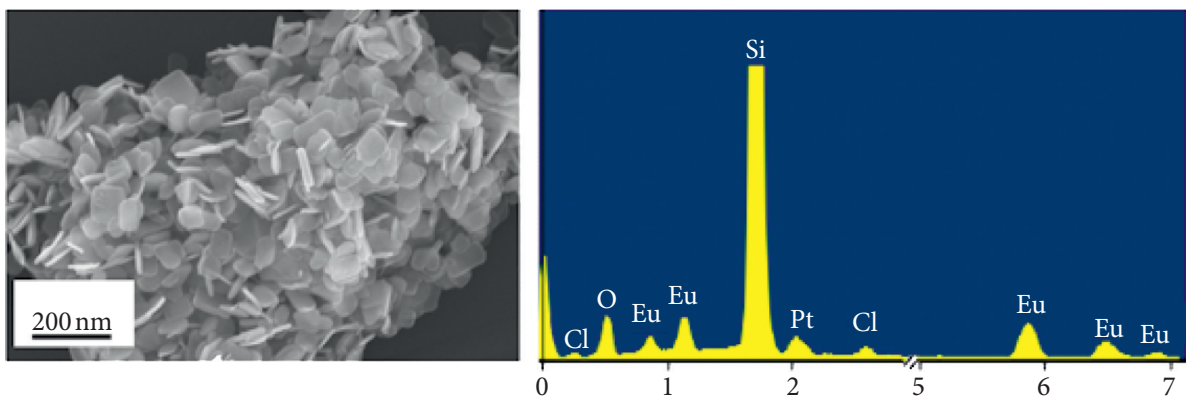

(b)
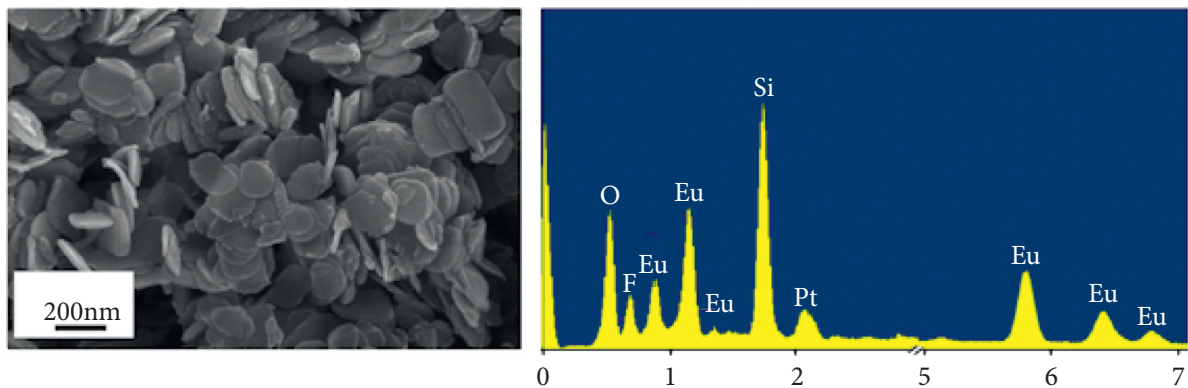

(c)

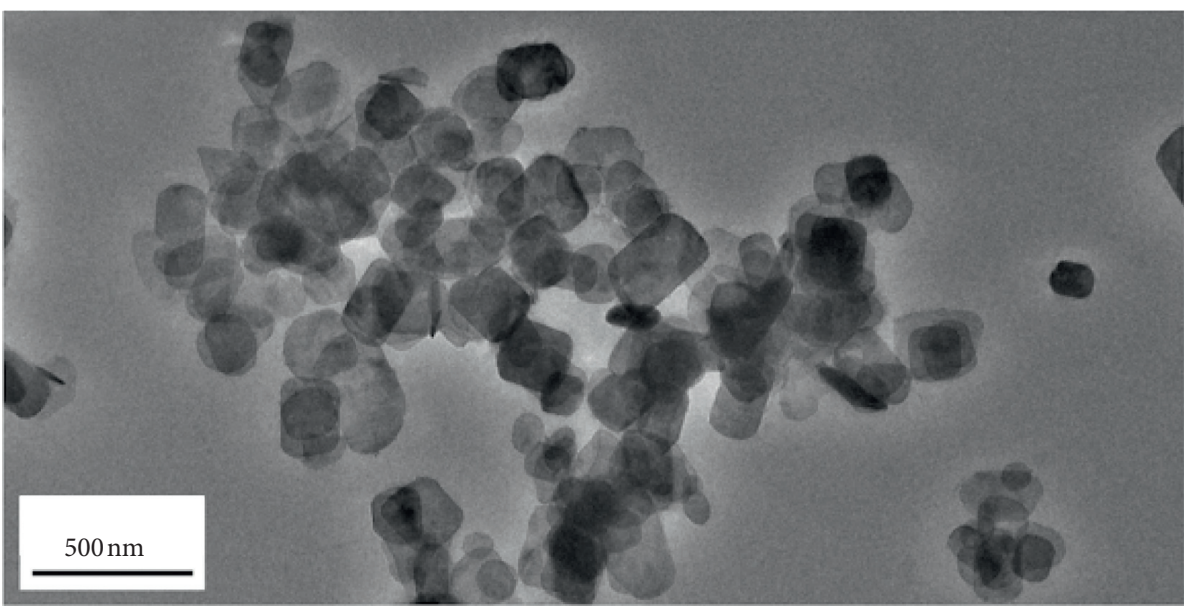

(d)

Figure 2: SEM and EDX images of (a) LEuH-Cl aggregates, (b) LEuH-flocs nanosheets, (c) LEuH-flocs + fluoride (Si and Pt come from the silicon wafer used in SEM analysis), and (d) TEM image of LEuH-flocs.

(BET) and Barrett-Joyner-Halenda (BJH) measurements) (Figure 8), whereas the pores in $\mathrm{LEuH}-\mathrm{Cl}$ aggregates have an average pore volume of $0.34 \mathrm{cc} / \mathrm{g}$ which is a characteristic of interparticular porosity and the LEuH-flocs nanosheets exhibit an average pore volume of $0.11 \mathrm{cc} / \mathrm{g}$ that is a characteristic of lack of porosity. In addition, after the BET 

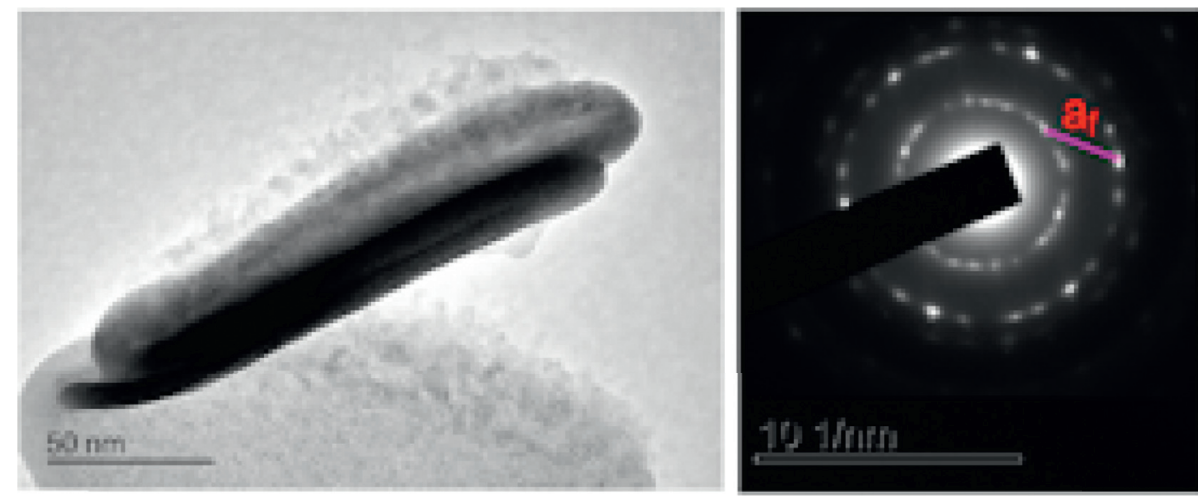

(a)
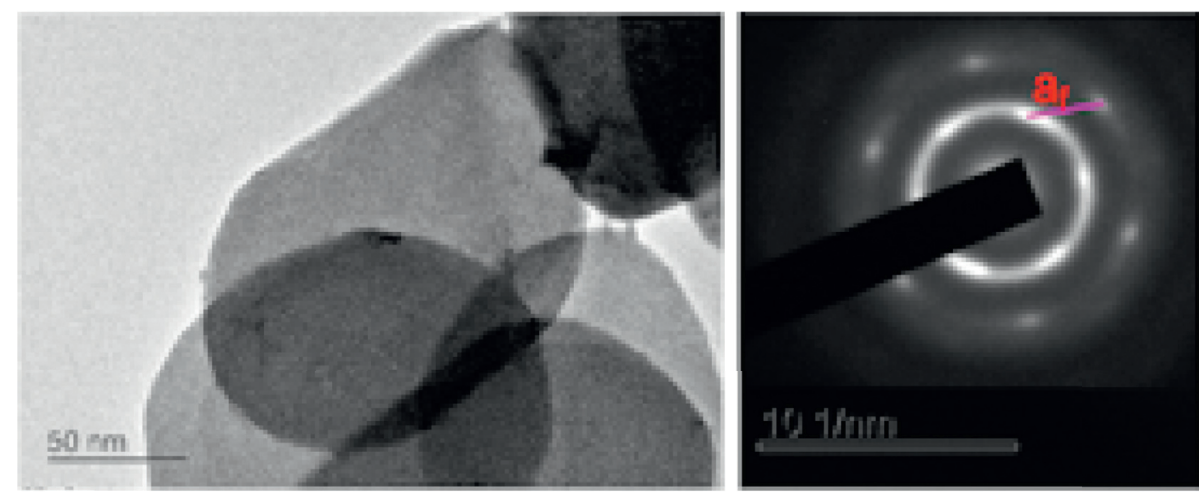

(b)
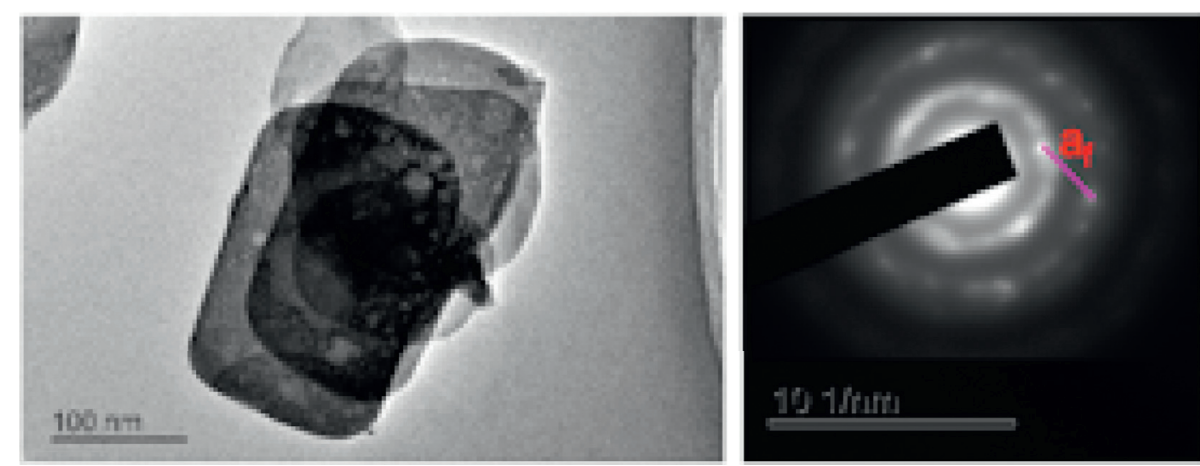

(c)

FIgURE 3: HRTEM and SAED images of (a) LEuH-Cl aggregates, (b) LEuH-flocs nanosheets, and (c) LEuH-flocs + fluoride ions.

experiments, the LEuH-flocs do not regain their original position as can be seen from the low pressure area in the isotherm where the two graphs (adsorption/desorption) should be a single line if the original structure is regained [21]. This clearly indicates the unstacked nature of the unilameller LEuH-flocs which lie on their $c$ axis and a change in pressure leads to an increase in their randomness.

\subsection{Application of the Unilameller LEuH-Flocs Nanosheets in} Fluoride Adsorption Experiments. Ion exchange reaction of unilameller LEuH-flocs nanosheets in a fluoride aqueous solution is proposed to proceed via equation (2). The reaction mechanisms are schematically represented in Figure 9. The fluoride sorption reaction was monitored titrimetrically using chloride concentration in the supernatant solution after the ion exchange reactions. The reaction was found to complete in 2 minutes:

$$
\begin{aligned}
& {\left[\mathrm{Eu}_{8}(\mathrm{OH})_{20}\left(\mathrm{H}_{2} \mathrm{O}\right)_{n}\right] \mathrm{Cl}_{4(s)}+4 \mathrm{NaF}_{(\mathrm{aq})}} \\
& \quad \longrightarrow\left[\mathrm{Eu}_{8}(\mathrm{OH})_{20}\left(\mathrm{H}_{2} \mathrm{O}\right)_{n}\right] \mathrm{F}_{4(s)}+4 \mathrm{NaCl}_{(\mathrm{aq})}
\end{aligned}
$$

The sorption experiments of fluoride anions from aqueous media were carried out with the unilameller LEuHflocs nanosheets and compared to $\mathrm{LEuH}-\mathrm{Cl}$ aggregates for 6 minutes (Figure 10). Unilameller LEuH-flocs nanosheets had the highest fluoride loading capacity of $40 \mathrm{mmol} / \mathrm{g}$ as compared to $\sim 20.0 \mathrm{mmol} / \mathrm{g}$ exhibited by $\mathrm{LEuH}-\mathrm{Cl}$ aggregates (Figure 10). Note that $\mathrm{LDH}-\mathrm{Cl}(\mathrm{Mg} / \mathrm{Al}$ with a molar ratio of $0.67: 0.33$, respectively) materials exhibit adsorption 


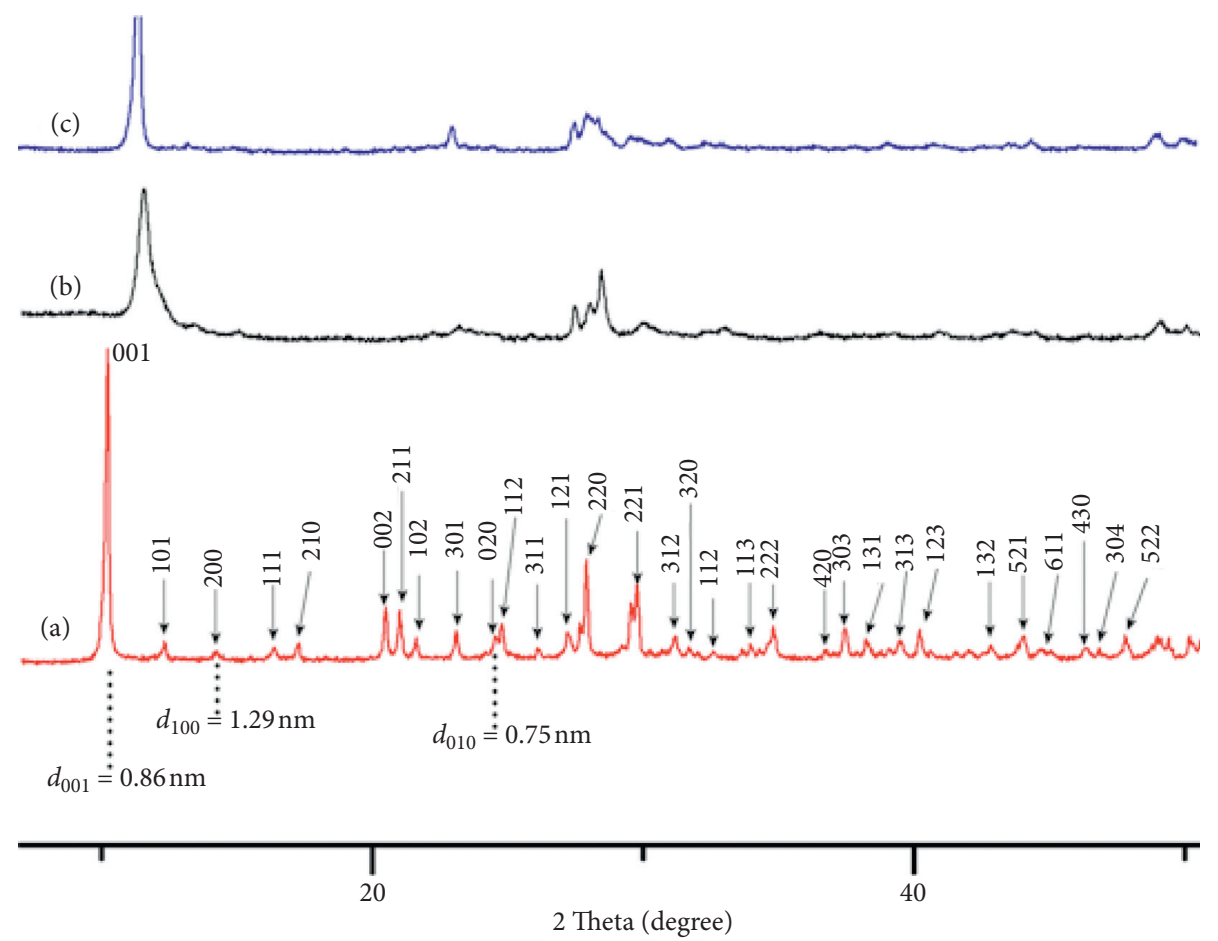

FIGURE 4: XRD patterns of (a) LEuH-Cl aggregates, (b) LEuH-flocs nanosheets, and (c) LEuH-flocs + fluoride ions.
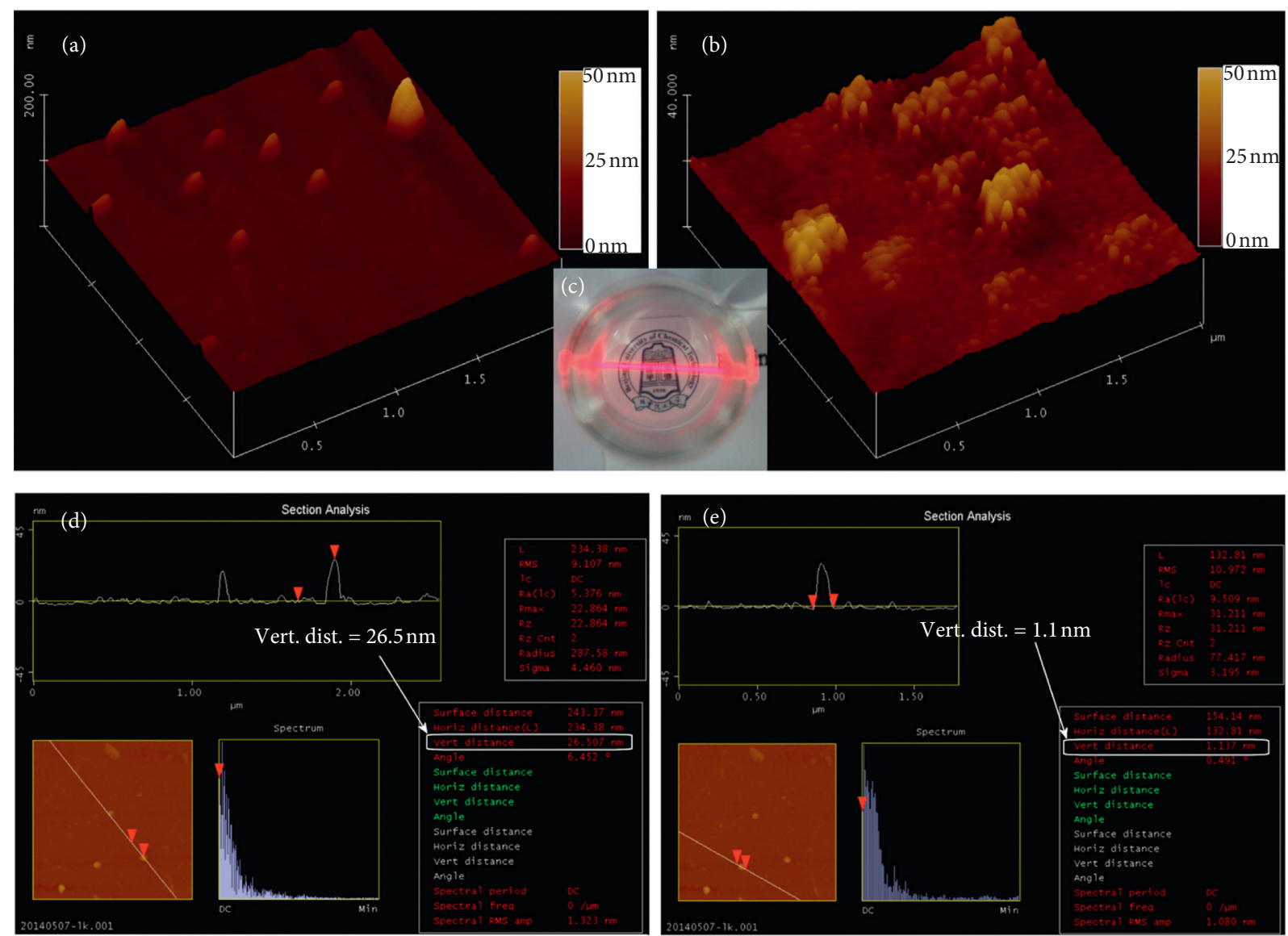

Figure 5: AFM diagrams of (a) LEuH-Cl aggregate material, (b) LEuH-flocs nanosheets, (c) the dispersion of an incident light by an aqueous colloidal solution of LEuH-flocs nanosheets $(\mathrm{pH}=7)$ demonstrating "the Tindal effect" of the dissolved powder, (d) AFM analysis of LEuH$\mathrm{Cl}$ aggregates, and (e) AFM analysis of LEuH-flocs nanosheets. 


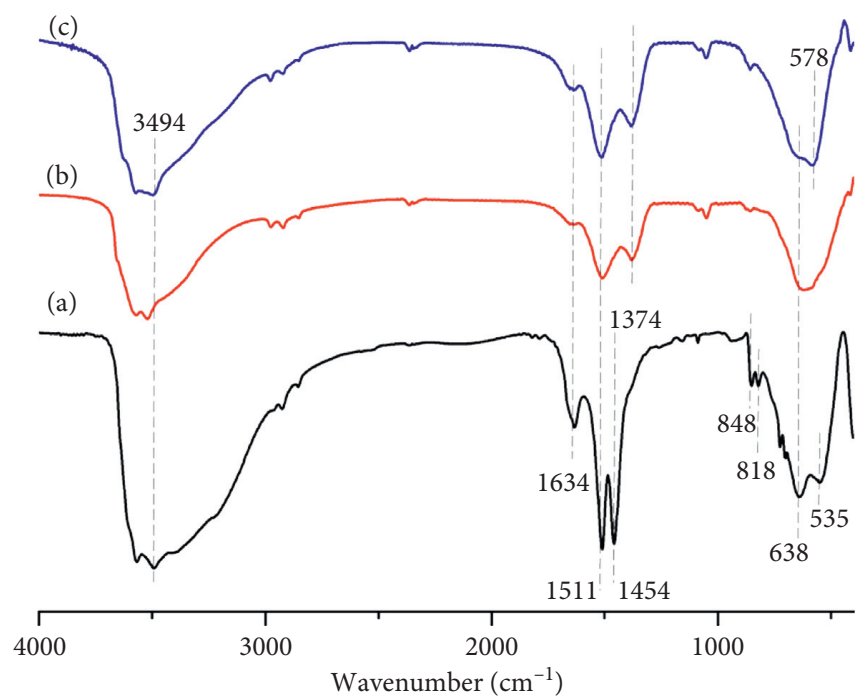

FIGURE 6: FTIR absorption patterns of (a) LEuH-Cl aggregates, (b) LEuH-flocs nanosheets, and (c) LEuH-flocs + fluoride ions.

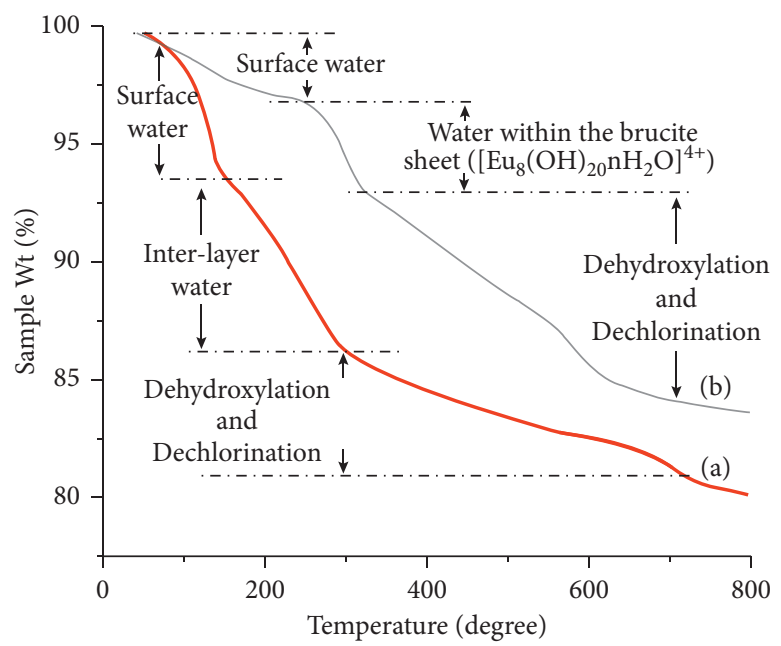

FigurE 7: Thermogravimetric analysis of (a) LEuH-Cl aggregates and (b) LEuH-flocs nanosheets.

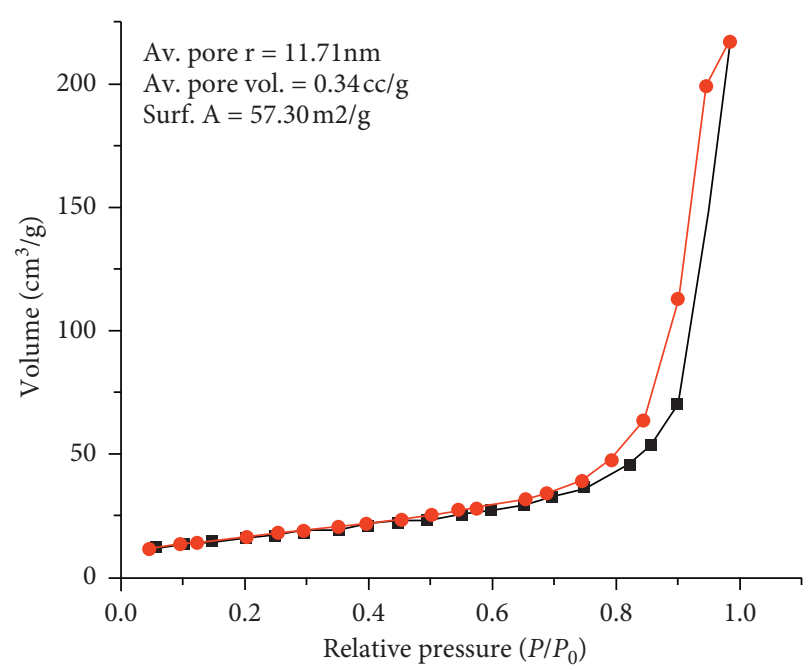

(a)

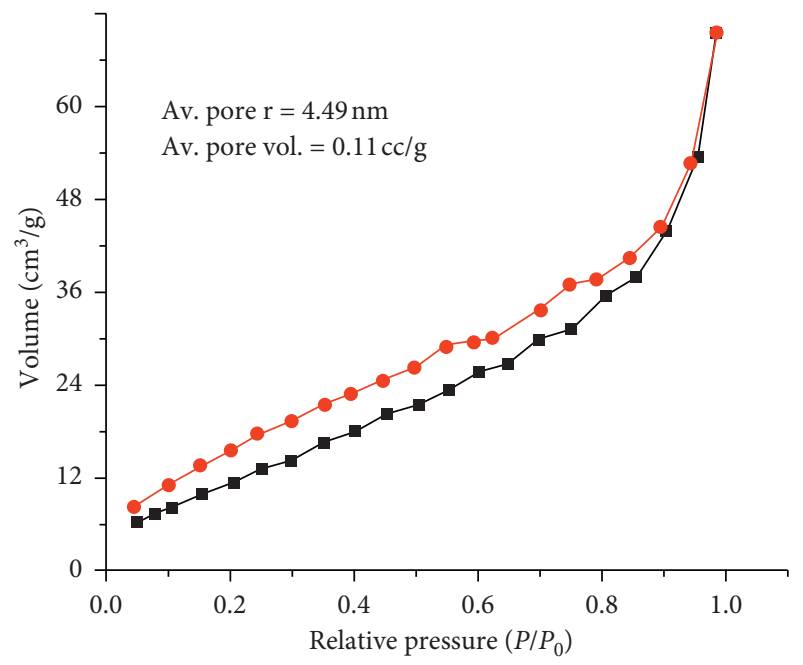

(b)

FIGURE 8: BET isotherms and BJH information of (a) LEuH-Cl aggregates and (b) LEuH-flocs nanosheets. 


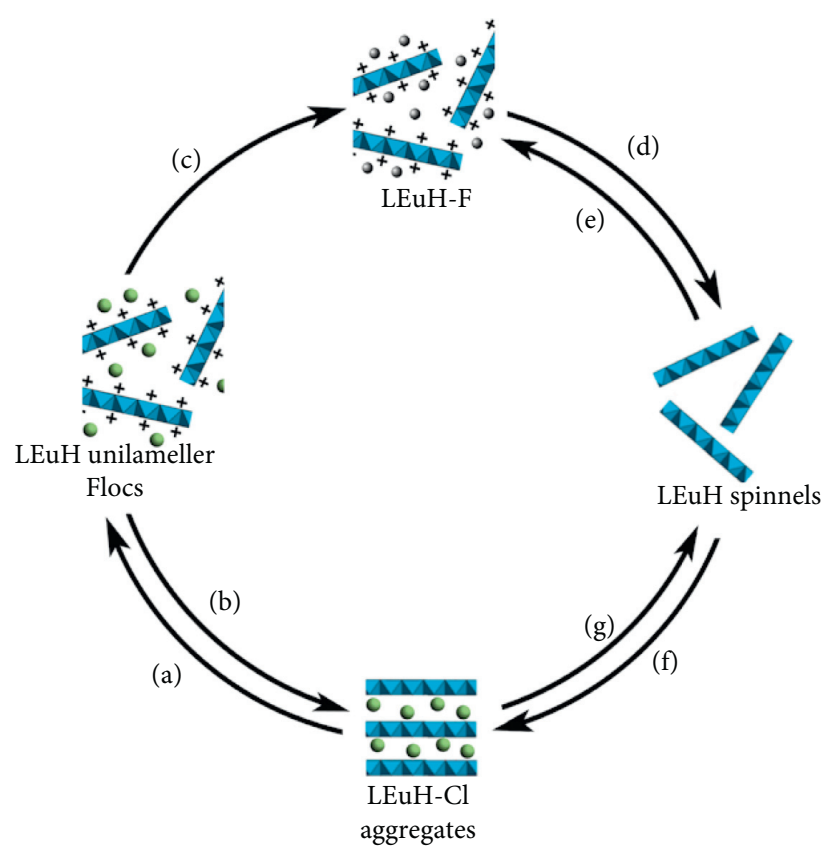

FIGURE 9: Schematic diagram representing the fluoride sorption process using layered rare-Earth hydroxides unilameller flocs as sorbents: (a) flocculation, (b) self-assembly, (c) fluoride adsorption, (d) calcination, (e) fluoride adsorption, (f) chloride adsorption, and (g) calcination.

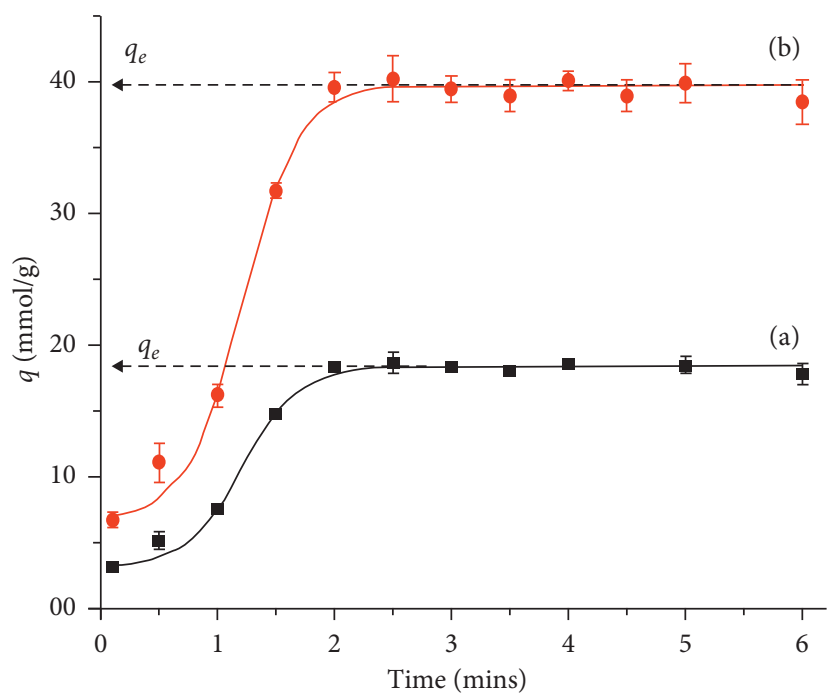

Figure 10: Kinetic studies for fluoride sorption from aqueous solutions by layered rare-Earth hydroxides: (a) LEuH-Cl aggregates; (b) LEuH-flocs nanosheets. $q_{\mathrm{e}}$ maximum adsorbed amount; $\mathrm{pH}=7$, temperature $=298 \mathrm{~K}$, and mass of sorbent $=0.2 \mathrm{~g}$.

capacities of $3.3 \mathrm{mmol} / \mathrm{g}$ [22]. Hence, the newly synthesized unilameller LEuH-flocs provide an effective and fast chemisorption recyclable nanosorbent material reported so far for fluoride separation from water.

The sorption mechanisms in unilameller LEuH-flocs nanosheets are purely attributed to chemisorption as its data fit perfectly with the Langmuir model (Figure 11) [23]. This is further supported with the type iii isotherm recorded with its BET isotherms (Figure 8). In contrast, $\mathrm{LEuH}-\mathrm{Cl}$ aggregates sorption mechanisms could be attributed to both physisorption mechanism and chemisorption mechanisms due to its type ii BET isotherm and the low $R^{2}$ values of the Langmuir model [21]. Specifically, the adsorption in LEuH$\mathrm{Cl}$ (hydrotalcite-like compounds) is initiated at the edges (physisorption mechanism) followed by ion exchange (chemisorption).

Anion adsorption behaviour of hydrotalcite-like compounds has been previously reported to occur at their edges through physisorption mechanisms [24-26]. However, delamination of $\mathrm{LEuH}-\mathrm{Cl}$ aggregate materials into unilameller LEuH-flocs nanosheets provides a new pathway in which the exposed chloride ions are easily exchanged with fluoride ions 


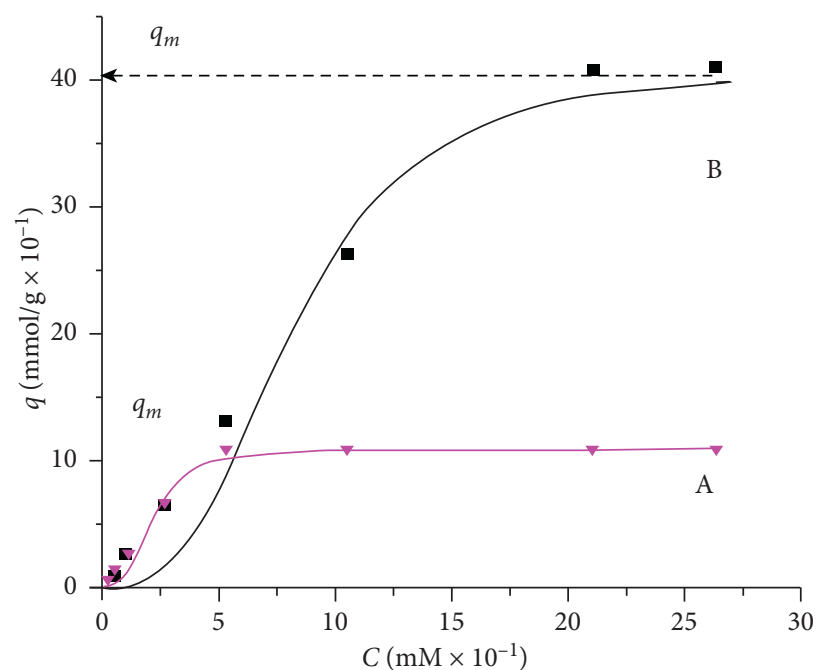

(a)

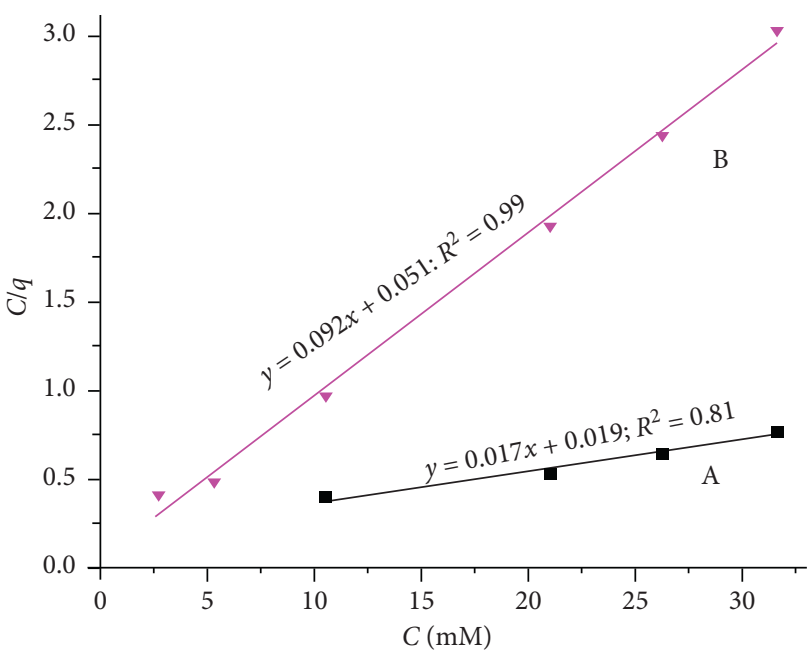

(b)

FIGURE 11: (a) Optimal sorbed amounts of fluoride anions from aqueous media; (b) Langmuir fit curves for (A) LEuH-Cl aggregates and (B) LEuH-flocs nanosheets.

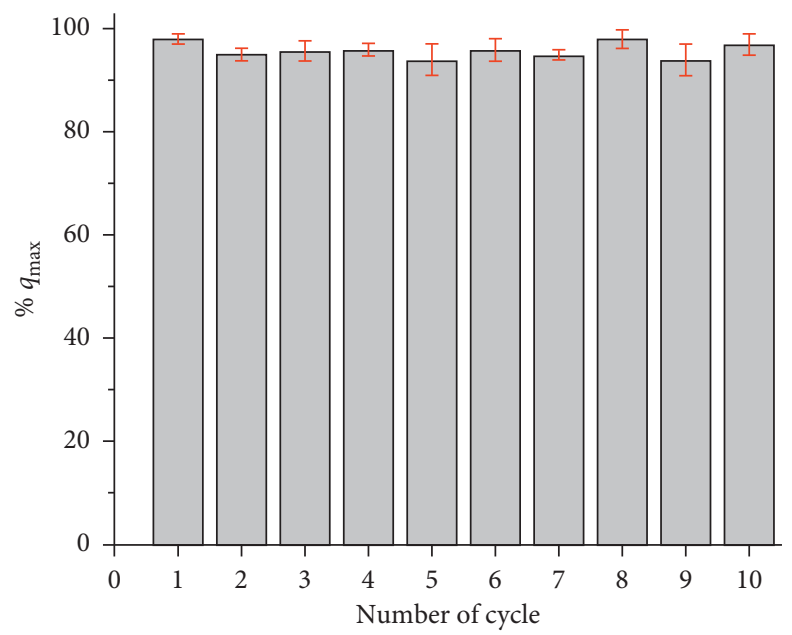

FIGURE 12: Recycling of the synthesized LEuH adsorbent in fluoride adsorption from aqueous solutions; $100 \% q_{\max }=40 \mathrm{mmol} / \mathrm{g}$; $\mathrm{pH}=7$; temperature $=298 \mathrm{~K}$; mass of sorbent $=0.2 \mathrm{~g}$. In cycle 1 , we used LEuH-flocs, and in the subsequent cycles, we use LEuH-spinels obtained after calcination of LEuH-flocs at $500^{\circ} \mathrm{C}$ as sorbent materials.

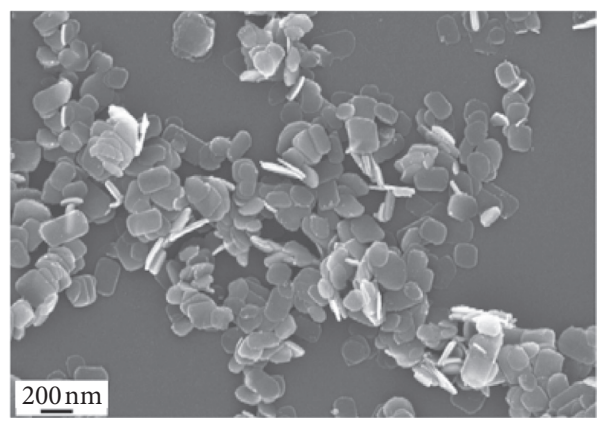

(a)

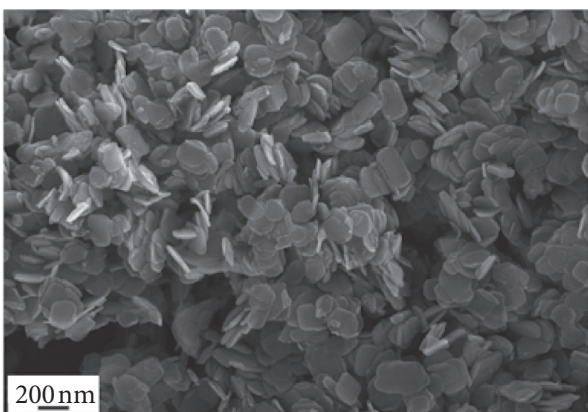

(b)

Figure 13: Continued. 


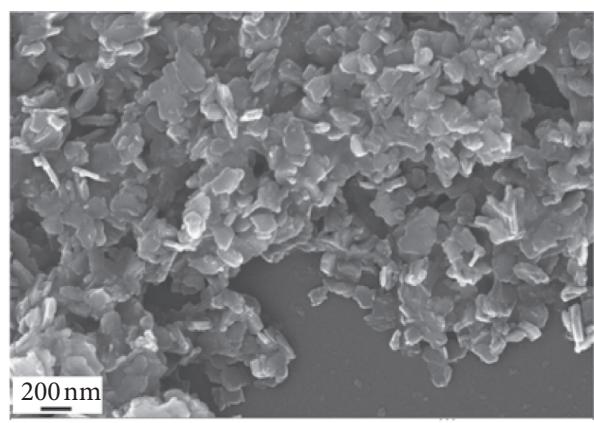

(c)

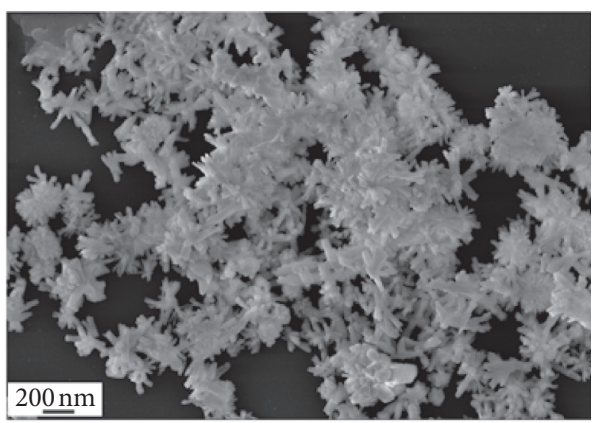

(d)

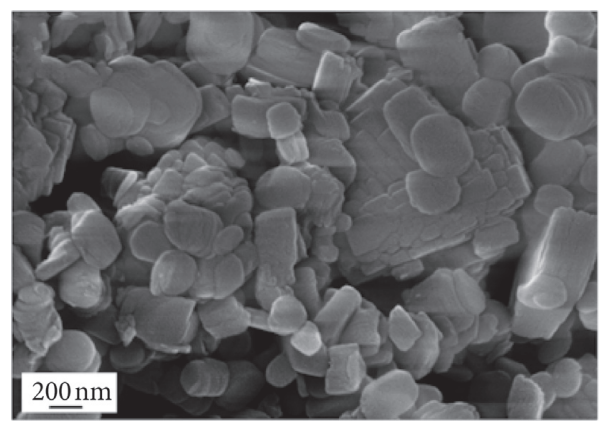

(e)

Figure 13: SEM images of (a) LEuH-flocs, (b) LEuH-flocs + fluoride ions, (c) LEuH-spinels obtained after calcination of LEuH-flocs at $500^{\circ} \mathrm{C}$, (d) LEuH-fluoride adsorbed sample using LEuH-spinels as adsorbent, and (e) self-assembly of LEuH-flocs with $\mathrm{NaCl}$ to reproduce the original LEuH-Cl aggregates.

from aqueous media. The reaction is fast and effective and has a higher fluoride loading rate than all other reported fluoride adsorbents [27].

The chemisorption process is further verified by the $\mathrm{FHF}^{-}$covalent bond that shows FTIR vibrations at $578 \mathrm{~cm}^{-1}$ (Figure 6) $[28,29]$. The chemisorption process does not interfere with the surface morphology of the unilameller LEuH-flocs nanosheets as is depicted in the images taken after the adsorption experiments by both SEM and HRTEM (Figures 2 and 3). In addition, the XRD patterns of the fluoride-adsorbed unilameller LEuH-flocs nanosheets have similar peaks to the starting materials LEuH-flocs (Figure 4).

After calcination at $500^{\circ} \mathrm{C}$ to remove the adsorbed fluoride ions, the resultant $\mathrm{LEuH}$-spinels were reused in fluoride adsorption for at least ten times giving similar adsorption capacities (Figure 12). It also noted that the spinels could also be dispersed in a $\mathrm{NaCl}$ solution (1 M) to reconstruct to the original $\mathrm{LEuH}-\mathrm{Cl}$ starting material (Figure 13). It is however observed that when LEuH calcined spinels are used directly to adsorb fluoride ions, the resultant morphology is different from LEuH-flocs material (Figure 13(d)). However, this change in morphology does not affect adsorption capacity as can be seen from subsequent reuse experiments (Figure 12).

\section{Conclusions}

In summary, we have been able to isolate unilameller nanosheets from a colloidal solution of europium-containing layered rare-Earth hydroxide material ( $\mathrm{LEuH}-\mathrm{Cl})$ by changing its $\mathrm{pH}$ from 6.5 to 11.5 in an aqueous medium. The resultant unilameller LEuH-flocs nanosheets exhibit fluoride chemisorption ability of $40 \mathrm{mmol} \cdot \mathrm{g}^{-1}$ as compared to $\mathrm{LEuH}$ $\mathrm{Cl}$ aggregates of $\approx 20.0 \mathrm{mmol} \cdot \mathrm{g}^{-1}$ and $\mathrm{LDH}-\mathrm{Cl}$ aggregates of $3.3 \mathrm{mmol} \cdot \mathrm{g}^{-1}$. And the chemisorption reaction is complete in two minutes with the resultant adsorbent being reusable after calcination at $500^{\circ} \mathrm{C}$.

\section{Data Availability}

All the necessary information required for replication of this work and/or conducting secondary analysis are included within the article.

\section{Conflicts of Interest}

The authors declare that they have no conflicts of interest.

\section{Acknowledgments}

This study was financially supported from National Research Fund of Kenya (2016/17). The RSC Allan Ure Bursary fund of 2017 and Jaramogi Oginga Odinga University of Science and Technology are acknowledged.

\section{References}

[1] T. Sasaki, Y. Ebina, T. Tanaka, M. Harada, M. Watanabe, and G. Decher, "Layer-by-Layer assembly of titania nanosheet/ polycation composite films," Chemistry of Materials, vol. 13, no. 12, pp. 4661-4667, 2001. 
[2] T. Sasaki and M. Watanabe, "Osmotic swelling to exfoliation. Exceptionally high degrees of hydration of a layered titanate," Journal of the American Chemical Society, vol. 120, no. 19, pp. 4682-4689, 1998.

[3] T. Sasaki, M. Watanabe, H. Hashizume, H. Yamada, and H. Nakazawa, "Macromolecule-like aspects for a colloidal suspension of an exfoliated titanate. Pairwise association of nanosheets and dynamic reassembling process initiated from it," Journal of the American Chemical Society, vol. 118, no. 35, pp. 8329-8335, 1996.

[4] L. Li, R. Ma, Y. Ebina, N. Iyi, and T. Sasaki, "Positively charged nanosheets derived via total delamination of layered double hydroxides," Chemistry of Materials, vol. 17, no. 17, pp. 4386-4391, 2005.

[5] A. Takagaki, T. Yoshida, D. Lu et al., "Titanium niobate and titanium tantalate nanosheets as strong solid acid catalysts," The Journal of Physical Chemistry B, vol. 108, no. 31, pp. 11549-11555, 2004.

[6] D. W. Kim, A. Blumstein, and S. K. Tripathy, "Nanocomposite films derived from exfoliated functional aluminosilicate through electrostatic layer-by-layer assembly," Chemistry of Materials, vol. 13, no. 5, pp. 1916-1922, 2001.

[7] S. Omwoma, W. Chen, R. Tsunashima, and Y.-F. Song, "Recent advances on polyoxometalates intercalated layered double hydroxides: from synthetic approaches to functional material applications," Coordination Chemistry Reviews, vol. 258-259, pp. 58-71, 2014.

[8] D.-L. Long and L. Cronin, "Pushing the frontiers in polyoxometalate and metal oxide cluster science," Dalton Transactions, vol. 41, no. 33, pp. 9815-9816, 2012.

[9] X. Wang, W. Chen, and Y.-F. Song, "Directional self-assembly of exfoliated layered europium hydroxide nanosheets and $\mathrm{Na}_{9} \mathrm{EuW}_{10} \mathrm{O}_{36} \cdot 32 \mathrm{H}_{2} \mathrm{O}$ for application in desulfurization," European Journal of Inorganic Chemistry, vol. 2014, no. 17, pp. 2779-2786, 2014.

[10] M. Adachi-Pagano, C. Forano, and J.-P. Besse, "Delamination of layered double hydroxides by use of surfactants," Chemical Communications, vol. 91, no. 1, pp. 91-92, 2000.

[11] M. Meyn, K. Beneke, and G. Lagaly, "Anion-exchange reactions of layered double hydroxides," Inorganic Chemistry, vol. 29, no. 26, pp. 5201-5207, 1990.

[12] B.-I. Lee and S.-H. Byeon, "Highly enhanced photoluminescence of a rose-like hierarchical superstructure prepared by self-assembly of rare-earth hydroxocation nanosheets and polyoxomolybdate anions," Chemical Communications, vol. 47, no. 14, pp. 4093-4095, 2011.

[13] K.-H. Lee and S.-H. Byeon, "Extended members of the layered rare-earth hydroxide family, $\mathrm{RE}_{2}(\mathrm{OH}) 5 \mathrm{NO}_{3} \cdot \mathrm{nH}_{2} \mathrm{O}(\mathrm{RE}=\mathrm{Sm}$, $\mathrm{Eu}$, and $\mathrm{Gd}$ ): synthesis and anion-exchange behavior," $\mathrm{Eu}$ ropean Journal of Inorganic Chemistry, vol. 2009, no. 7, pp. 929-936, 2009.

[14] H. Jeong, B.-I. Lee, and S.-H. Byeon, "Directional self-assembly of rare-earth hydroxocation nanosheets and paradodecatungstate anions," Dalton Transactions, vol. 41, no. 46, pp. 14055-14058, 2012.

[15] B.-I. Lee, J.-S. Bae, E.-S. Lee, and S.-H. Byeon, "Synthesis and photoluminescence of colloidal solution containing layered rare-earth hydroxide nanosheets," Bulletin of the Korean Chemical Society, vol. 33, no. 2, pp. 601-607, 2012.

[16] F. Geng, Y. Matsushita, R. Ma et al., "General synthesis and structural evolution of a layered family of $\operatorname{Ln}_{8}(\mathrm{OH})$ $20 \mathrm{Cl}_{4} \cdot \mathrm{nH}_{2} \mathrm{O}(\mathrm{Ln}=\mathrm{Nd}, \mathrm{Sm}, \mathrm{Eu}, \mathrm{Gd}, \mathrm{Tb}, \mathrm{Dy}, \mathrm{Ho}, \mathrm{Er}, \mathrm{Tm}$, and Y)," Journal of the American Chemical Society, vol. 130, no. 48, pp. 16344-16350, 2008.
[17] F. Geng, H. Xin, Y. Matsushita et al., "New layered rare-earth hydroxides with anion-exchange properties," Chemistry-A European Journal, vol. 14, no. 30, pp. 9255-9260, 2008.

[18] M. Ando, M. Tadano, S. Yamamoto et al., "Health effects of fluoride pollution caused by coal burning," Science of The Total Environment, vol. 271, no. 1-3, pp. 107-116, 2001.

[19] X. Qu, P. J. J. Alvarez, and Q. Li, "Applications of nanotechnology in water and wastewater treatment," Water Research, vol. 47, no. 12, pp. 3931-3946, 2013.

[20] Z. Barghouthi and S. Amereih, "Spectrophotometric determination of fluoride in groundwater using resorcin blue complexes," American Journal of Analytical Chemistry, vol. 3, no. 9, pp. 651-655, 2012.

[21] K. S. W. Sing, D. H. Everett, R. A. W. Haul et al., "Reporting physisorption data for gas/solid systems with special reference to the determination of surface area and porosity (Recommendations 1984)," Pure and Applied Chemistry, vol. 57, no. 4, pp. 603-619, 1985.

[22] T. Kameda, J. Oba, and T. Yoshioka, "Recyclable Mg-Al layered double hydroxides for fluoride removal: kinetic and equilibrium studies," Journal of Hazardous Materials, vol. 300, pp. 475-482, 2015.

[23] S. Azizian, "Kinetic models of sorption: a theoretical analysis," Journal of Colloid and Interface Science, vol. 276, no. 1, pp. 47-52, 2004.

[24] A. Ookubo, K. Ooi, F. Tani, and H. Hayashi, "Phase transition of Cl-Intercalated hydrotalcite-like compound during ion exchange with phosphates," Langmuir, vol. 10, no. 2, pp. 407-411, 1994.

[25] M. Jobbágy and A. E. Regazzoni, "Complexation at the edges of hydrotalcite: the cases of arsenate and chromate," Journal of Colloid and Interface Science, vol. 393, pp. 314-318, 2013.

[26] M. Jobbágy and A. E. Regazzoni, "Anion-exchange equilibrium and phase segregation in hydrotalcite systems: intercalation of hexacyanoferrate(III) ions," The Journal of Physical Chemistry B, vol. 109, no. 1, pp. 389-393, 2005.

[27] P. Miretzky and A. F. Cirelli, "Fluoride removal from water by chitosan derivatives and composites: a review," Journal of Fluorine Chemistry, vol. 132, no. 4, pp. 231-240, 2011.

[28] F. A. Miller and C. H. Wilkins, "Infrared spectra and characteristic frequencies of inorganic ions," Analytical Chemistry, vol. 24, no. 8, pp. 1253-1294, 1952.

[29] R. S. C. Smart and N. Sheppard, "Infrared and far infrared spectroscopic studies of the adsorption of water molecules on high-area alkali halide surfaces," Journal of the Chemical Society, Faraday Transactions 2, vol. 72, p. 707, 1976. 